\title{
El aprendizaje de la terminología mediante deeper learning
}

\section{Anna I. Montesinos López}

Universitat Politècnica de València, amontelo@idm.upv.es

\begin{abstract}
In this work we proposed a methodology by competences for the learning of the engineering terminology. Given the characteristics of such learning, an effective way is learning by developing the competences in the students. A methodology that brings together the competences for success is deeper learning, which gives students a high degree of motivation as well as the achievement of the main professional competences through the learning of terminology.
\end{abstract}

Keywords: engineering terminology, deeper learning, acquisition of terminology, educational competences.

\footnotetext{
Resumen

En este trabajo se propone una metodología por competencias para el aprendizaje de la terminología de las ingenierías. Dadas las características de dicho aprendizaje, una manera eficaz es el aprendizaje por el desarrollo de las competencias en el alumnado. Una metodología que reúne las competencias para el éxito es el deeper learning o aprendizaje profundo, el cual otorga al alumnado un alto grado de motivación así como el logro de las principales competencias profesionales mediante el aprendizaje de la terminología.
}

Palabras clave: terminología de las ingenierías, aprendizaje profundo o deeper learning, adquisición de la terminología, aprendizaje por competencias.

\section{Introducción}

Es evidente que la terminología específica de una materia se adquiere por medio del estudio de la propia materia específica. Es bien sabido por todos que el alumnado de una materia especializada específica no sólo aprende los contenidos y los conocimientos de dicha materia, sino que también adquiere la forma en la que estos se articulan, se expresan y se transmiten. No obstante, a menudo se debe aprender la terminología de una materia en otras lenguas diferentes a la que se adquirió, puesto que generalmente hay más de una lengua de uso especializada y el alumnado o el profesional debe ser competente en más de una lengua 
de especialidad, bien para la divulgación y la docencia, o bien para la gestión profesional, pongamos por caso. En nuestro trabajo, el alumnado de las asignaturas de Valencià Tècnic de la Universitat Politècnica de València, estudia la lengua y el discurso especializado dentro del contexto de las ingenierías. Una parte importante de esta formación es el aprendizaje de la terminología con la que se construyen los discursos y la comunicación de las ingenierías.

Tradicionalmente, el aprendizaje de la terminología ha estado ligado al estudio de listas de términos equivalentes en diversas lenguas. Con el tiempo y los resultados obtenidos, es ciento que se trata de una forma poco eficaz de aprendizaje de la terminología, puesto que sirve para superar un examen, pero no para su uso posterior en contextos diferentes de la vida profesional.

Las últimas tendencias de la neuroeducación apuntan que el cerebro necesita emocionarse para aprender y por lo tanto el modelo pedagógico basado en un alumnado como receptor pasivo no funciona. Por lo tanto, ya no sirve que el profesor ofrezca los contenidos y que el alumnado los reciba pasivamente.

Por todo esto, la didáctica de la terminología debe ser lo más integrada posible en el contexto de la especialidad y tener un aprendizaje significativo para el alumnado, es decir, los términos tienen que aprenderse dentro de los textos y los contextos específicos de las ingenierías para que el alumnado sienta su utilidad y su necesidad de uso. Para ello, como vemos en el presente trabajo, el alumnado consigue aprender la materia, que es la terminología propia de su ingeniería, mediante la práctica de la metodología del trabajo terminológico de forma colaborativa y la reflexión sobre su propio itinerario de aprendizaje.

\section{Objetivos}

El principal objetivo del aprendizaje de la terminología es el uso correcto y adecuado de la terminología de las ingenierías por parte del alumnado de las asignaturas de Valencià Tècnic de la Universitat Politècnica de València. Más concretamente, en este estudio nos referiremos a la asignatura de Valencià Tècnic aplicat a la informàtica i a les telecomunicacions de l'Escola Tècnica Superior d'Enginyeria Informàtica de dicha universidad. Así pues, para el logro del objetivo principal, el alumnado debe adquirir determinadas competencias, conocimientos y habilidades con el fin de la consecución del éxito formativo y de su futuro profesional.

Entre los objetivos de la innovación educativa destacamos la aplicación de un aprendizaje adecuado a los nuevos aprendizajes y al propio carácter de la institución, así como promover actitudes positivas hacia el uso de la terminología en el marco de la especialidad y sus implicaciones en la competencia comunicativa; también, el de crear un espacio para aplicar una experiencia novedosa que contribuya a un mejor uso terminológico.

Según la fundación Hewlett (Tourón, 2016a), el método deeper learning es un enfoque educativo que tiene como objetivo potenciar seis competencias, que son las siguientes:

- dominar la materia

(cc) EY-NC-ND 2018, Universitat Politècnica de València

Congreso IN-RED (2018) 
- $\quad$ pensar críticamente y resolver problemas complejos

- trabajar colaborativamente

- comunicar efectivamente

- $\quad$ aprender a aprender o aprendizaje autodirigido

- desarrollar una mentalidad académica incremental y positiva

Esta última competencia, la Fundació Jaume Bofill (2017) la define como un alumnado confiado en sus propias capacidades y que ve la relevancia del trabajo que desarrolla, ya que se vinculan los aprendizajes a los retos y a los problemas reales.

Por lo que se refiere a los contenidos para el aprendizaje de la terminología (Cabré, 1992; Franquesa, 2008; TERMCAT, 2010), los objetivos específicos de la materia terminológica que debe lograr el alumnado son los ítems siguientes:

- Conocer los mecanismos de creación de los términos asociados a las ingenierías.

- Conocer las fuentes terminológicas de autoridad en línea y los recursos terminológicos electrónicos.

- $\quad$ Proponer adaptaciones de los términos no integrados todavía en las fuentes terminológicas de autoridad o neologismos.

- Resolver problemas terminológicos que se plantean con los neologismos.

- Conocer la metodología del trabajo terminológico con el fin de elaborar un vocabulario básico multilingüe de especialidad.

- Saber desarrollar un recurso terminológico adecuado a un contexto determinado y a un perfil de necesidades.

- Buscar en fuentes textuales válidas para la extracción de términos.

- Trabajar de manera colaborativa en mapas conceptuales y campos semánticos.

Una vez planteados los objetivos específicos del aprendizaje de la terminología en las asignaturas de lenguaje de especialidad, pasamos a exponer la metodología a utilizar para la consecución de los objetivos marcados.

\section{Metodología y desarrollo}

Como ya hemos citado anteriormente, el método propuesto es el llamado deeper learning o aprendizaje profundo. Este es una herramienta de transformación educativa que tiene como fin acelerar el aprendizaje profundo, por lo que se refiere a las competencias, los conocimientos y las habilidades que el alumnado debe desarrollar en su formación para lograr el éxito.

Tourón (2016a) plantea que estas competencias implican tres dominios interrelacionados: cognitivo, interpersonal e intrapersonal. En el dominio cognitivo, el alumnado debe lograr una sólida base académica en la materia. A medida que el alumnado domina el contenido, será más capaz de trasferir el conocimiento a otras situaciones o tareas y deben analizar y sintetizar la información, reconocer patrones y relaciones con el fin de identificar y resolver problemas y evaluar la eficacia de las soluciones propuestas.

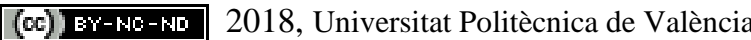


En el dominio interpersonal, el alumnado trabaja colaborativamente en las tareas y genera trabajo compartido, así como resuelve los problemas en grupo. También aprende a comunicar eficazmente los conceptos de forma lógica y significativa.

En el dominio intrapersonal, el alumnado aprende cómo supervisar y dirigir su propio aprendizaje, reconocer lo que saben y lo que no, identificar obstáculos para su aprendizaje y plantear estrategias de resolución. En el desarrollo de una mentalidad de crecimiento académica, el alumnado es capaz de verse con éxito y comportamientos académicos positivos y productivos.

En esta metodología por competencias, el profesorado se convierte en un verdadero guía del aprendizaje, el cual hace ver al alumnado que este es el responsable de su propio proceso de aprendizaje. De esta manera, Martínez, McGrath \& Foster (2016), también Tourón (2016b), proponen que para preparar el alumnado de cara a los nuevos retos, el profesorado debe:

- Empoderar al alumnado como aprendices.

- Contextualizar el conocimiento haciéndolo coherente.

- Conectar el aprendizaje con experiencias del mundo real.

- Extender el aprendizaje más allá del centro educativo.

- Inspirar a los estudiantes personalizando sus experiencias de aprendizaje.

- Incorporar la tecnología decididamente para enriquecer, más que automatizar, el aprendizaje.

Así, la consecución de los objetivos se realiza gracias a las prácticas educativas por consecución de las competencias. De esta manera, el dominio de la materia terminológica se produce gracias a la práctica de las actividades y proyectos relacionados con cada una de las competencias.

El alumnado realiza lecturas programadas de los mecanismos de formación terminológica antes de las sesiones presenciales con el fin que puedan resolver determinadas actividades propuestas por el profesorado para el dominio de dichos mecanismos. Para ello, se utilizan diversas posibilidades de la aplicación Poliformat.

En una fase posterior, cuando ya son conocedores de los mecanismos de formación terminológica, y con el fin de trabajar el pensamiento crítico y la resolución de problemas complejos, el alumnado lleva a cabo otras actividades prácticas donde sistematizan las características de la terminología de un campo específico y deben buscar soluciones a los problemas que plantean los términos que todavía no se han adaptado o neologismos, bien porque todavía se está valorando o bien porque son bastante recientes. Una de las opciones que tienen para el proyecto es realizar las consultas electrónicas al organismo que es autoridad en la materia terminológica (el TERMCAT), así como participar en las sugerencias de las propuestas neológicas de dicho organismo. Asimismo, tienen que realizar un control de calidad en las definiciones según los parámetros establecidos.

En cuanto al trabajo colaborativo, el alumnado debe conocer la terminología de su propio campo profesional y de la metodología del trabajo terminológico. Para ello, en grupos, tienen que elaborar un mapa conceptual y los campos semánticos mediante la extracción de

(cc) EY-NC-ND 2018, Universitat Politècnica de València

Congreso IN-RED (2018) 
términos de textos electrónicos de la especialidad. Deben debatir qué términos formaran parte del vocabulario terminológico que están elaborando y sus equivalencias en otras lenguas para establecer sus propuestas neológicas.

La comunicación efectiva es sumamente importante tanto en la forma oral como en la escrita. Los grupos exponen a sus compañeros y compañeras el trabajo realizado teniendo en cuenta los parámetros asignados, tanto formales como metodológicos de la materia. Se deja un espacio temporal para el debate en el aula en cuanto a los posibles problemas terminológicos encontrados y sus soluciones.

Además, tienen que comunicar por escrito de forma efectiva mediante la presentación de una memoria individual que recoge los procedimientos de formación terminológica empleados en el vocabulario terminológico realizado en grupo, así como el planteamiento de las dificultades encontradas y sus soluciones. Así mismo, deben incluir en la memoria algunos ítems que se refieren a su estilo de aprendizaje y la satisfacción con el método de aprendizaje empleado en la asignatura.

El desarrollo de una mentalidad académica positiva se produce en todo el proceso de aprendizaje, pero especialmente en la consideración y la aplicación de las soluciones que el alumnado plantea, así como mediante el autoconocimiento del propio aprendizaje terminológico, puesto que incorpora un grado de confianza en su propia capacidad y competencia.

Las fases en las que se desarrolla el aprendizaje de la terminología mediante esta metodología son las siguientes:

En la primera fase, se establecen los objetivos, método y actividades con el alumnado.

En la segunda fase, se procede a las lecturas y debates en clase sobre los mecanismos de formación terminológica.

En la tercera fase, se le propone, al alumnado, actividades en grupo que implican la aplicación de la resolución de problemas terminológicos, una vez conocen las tendencias terminológicas y los organismos de consulta.

En la cuarta fase, los grupos de alumnos deben elegir una área terminològica de su campo de conocimiento y elaborar autónomamente un vocabulario terminológico.

En la quinta fase, los grupos presentan su trabajo delante de la clase i explican su proceso de elaboración y los resultados más importantes.

En la última fase, el alumnado entrega a la profesora una memoria individual del trabajo realizado (donde se valoran todas las fases, así como su efectividad y satisfacción con estas).

Finalmente, la evaluación, la cual forma parte del continuo proceso de enseñanzaaprendizaje, recoge la valoración cuantitativa de las tareas y actividades siguientes:

- Actividades de aproximación y asentamiento de la metodología terminológica.

- Actividades de búsqueda y propuesta terminológica.

(cc) EY-NC-ND 2018, Universitat Politècnica de València

Congreso In-Red (2018) 
- Presentación oral en grupo a elegir entre un cartel de divulgación terminológica y un vocabulario terminológico.

- Presentación escrita en grupo del proceso de elaboración del recurso terminológico.

- Dosier de la evolución llevada a cabo y de las dificultades encontradas, así como la temporalización del trabajo. Incluye un resumen de cómo se ha aplicado la metodología del trabajo terminológico.

\section{Resultados}

En cuanto a los resultados obtenidos con el ejercicio de la metodología del aprendizaje profundo, expondremos los que hacen referencia a la asignatura Valencià tècnic aplicat a la informàtica i a les telecomunicacions de l'Escola Tècnica Superior d'Enginyeria Informàtica con un total de 32 alumnos y alumnas.

El estudio se ha realizado desde dos perspectivas: una cuantitativa y otra cualitativa. Por lo que se refiere a la primera, se ha pasado unas cuestiones escritas al alumnado que debía incorporar a la memoria escrita que se le solicitaba en la última fase del aprendizaje, y que consta de tres preguntas:

- Has aprendido mejor la terminología con esta metodología?

- Has aprendido más que la terminología propiamente dicha?

- Estás satisfecho/a con esta metodología?

En cuanto a la primera pregunta, un $87,5 \%$ ha contestado que sí; en cuanto a la segunda, un $93,7 \%$ ha contestado que sí; y, en cuanto a la tercera, un $84,3 \%$ ha respondido que sí en general.

Desde la perspectiva cualitativa, al final del cuadrimestre, se ha mantenido una conversación individual de diez minutos con 10 alumnos voluntarios que han expuesto sus ideas alrededor de la metodología utilizada y su aprendizaje terminológico (según las tres preguntas del dosier) y que pueden explicar los resultados obtenidos de forma cuantitativa.

En este sentido, la primera cosa que han remarcado era que aunque aprendían más y mejor les suponía un mayor esfuerzo que estudiar una lista de palabras de cara a un examen. A pesar de ello, el desarrollo de las seis competencias no es posible mediante el estudio del listado. No obstante, han reconocido una mayor motivación y implicación tanto en la materia como en la asignatura mediante este método, así como un aumento en su autonomía, ya que conocen los mecanismos de búsqueda y solución de problemas, además de convertirse ellos en los protagonistas. Finalmente, un aspecto que han considerado muy positivo era la reflexión sobre el propio proceso de aprendizaje y un aumento en la toma de conciencia sobre el mejor método de aprendizaje para sí mismo.

(c) EY-NC-ND 2018, Universitat Politècnica de València

Congreso IN-RED (2018) 


\section{Conclusiones}

El aprendizaje de la terminología de las ingenierías mediante los métodos tradicionales no han generado buenos resultados a lo largo de su enseñanza, por ello la búsqueda de métodos innovadores que incorporen las competencias necesarias para la formación con éxito del alumnado siempre son necesarias. Este aprendizaje llevado a cabo mediante un conjunto de competencias no sólo ha beneficiado el interés por el aprendizaje de la terminología y del método del trabajo terminológico, sino que además ha motivado en gran manera al alumnado a su realización, así como a su autoconciencia sobre su proceso de aprendizaje, lo que le ha llevado a un mayor desarrollo del aprender a aprender, del trabajo colaborativo y de la comprensión de la materia, según los datos aportados por el alumnado en el dosier final de la asignatura. Finalmente, podemos concluir que con el método deeper learning, nuestros alumnos se han beneficiado enormemente de una actitud positiva en el aprendizaje de la materia terminológica, gracias a un aumento de la motivación y la implicación del alumnado en su aprendizaje y en la asignatura.

\section{Referencias}

CABRÉ, M.T. (1992). La terminologia. La teoria, els mètodes, les aplicacions. Barcelona : Empúries. FRANQUESA, E. (2008). La terminologia. Un mirall del món. Barcelona : Editorial UOC.

FUNDACIÓ JAUME BOFILL (2017). eer learning. Descobreix les 6 competències clau de l'aprenentatge profund.

$<$ http://www.educaciodema.es/tendencies/deeper-learning/> [Consulta: 15 de marzo de 2018].

MARTÍNEZ, M.R., MCGRATH, D.R. y FOSTER, E. (2016). How Deeper Learning Can Create a New Vision for Teaching. Arlington: The National Commission on Teaching \& America's Future.

TERMCAT (2010). El diccionari terminològic. Barcelona -Vic: TERMCAT-Eumo editorial. TOURÓN, J. (2016a). El rol del profesor en un aprendizaje más profundo (Deep learning). $<$ http://www.javiertouron.es/el-rol-del-profesor--en-un-aprendizaje/> [Consulta: 15 de marzo de 2018].

TOURÓN, J. (2016b). Hacia un aprendizaje más profundo : Deeper learning in Action!.

$<$ http://www.javiertouron.es/hacia-un-aprendizaje-mas-profundo/> [Consulta: 15 de marzo de 2018] 